\title{
Brittleness Logging Evaluation of Shihezi Formation in Yanchang Gas Field in Ordos Basin Based on Rock Mechanical Characteristics
}

\author{
Zhenhua $\mathrm{Li}^{1 *}$, Ke Gai ${ }^{1}$, Zhanjun Chen ${ }^{1}$, Suya Zhang ${ }^{2}$, Ning Sun ${ }^{1}$, and Xiangyang $\mathrm{Li}^{3}$ \\ ${ }^{1}$ School of Energy Engineering, Longdong University, 745000, Qingyang, China \\ ${ }^{2}$ School of Foreign Languages, Longdong University, 745000, Qingyang, China \\ ${ }^{3}$ Gansu Coalfield Geology Bureau, 745000, Qingyang,China
}

\begin{abstract}
Brittleness determines the effect of reservoir fracturing and is important for increasing the production of unconventional oil and gas. The reservoir of Yanchang gas field is characterized by low porosity, low permeability and strong heterogeneity, which make it difficult to produce industrial gas flow under natural conditions. Triaxial compression tests in sandstone samples of Shihezi formation in Yanchang gas field show that the main fracturing mode is multiple horizontal splitting, the main cracks are completely fractured, and the brittleness index ranges from $46.1 \%$ to $51.4 \%$. After S-wave velocity model in the study area is established, the conversion relation of dynamic and static mechanical parameters could be obtained, that is, $E_{s}=0.4142 E_{d}+10.769\left(\mathrm{R}^{2}=0.8387\right)$, and $\mu_{s}=1.1076 \mu_{d}-0.068\left(\mathrm{R}^{2}=0.7366\right)$, according to which, the dynamic mechanics parameters calculated by well logging can be adjusted, and then the reservoir brittleness could be quantitatively evaluated. Combining with the brittleness index calculated by mineral component method, it can be concluded that the brittleness calculated by well logging is reliable and the brittleness of Shihezi formation in Yanchang gas field is high, which is beneficial for reservoir fracturing.
\end{abstract}

\section{Introduction}

Brittleness is a key content in unconventional oil and gas geology and an important parameter for stratum drillability analysis and favorable fracturing stratum selection. The higher the brittleness is, the easier it is to form complex fracture network ${ }^{[1 \sim 3]}$. Therefore, accurate identification of reservoir with high brittleness is helpful to improve the production of gas well. Rock mechanical properties are closely related to brittleness, so the study of rock mechanical properties and brittleness is the key to reservoir fracturing ${ }^{[4]}$.

Yanchang gas field is located in the eastern part of Yishan slope of Ordos Basin (Fig. 1). In Paleozoic era, Yanchang gas field mainly experienced two periods of early continental margin sea basin formation and late craton formation. During the middle Permian sedimentary period, delta deposits dominated Yanchang gas field. Because of frequent alternation of continental sedimentary environment, reservoir is characterized by strong heterogeneity, complex lithological composition, diverse pore structure, low porosity and permeability. It is difficult to produce industrial gas flow under natural conditions, so man-made fracturing is needed to change its physical properties.

In this paper, on the basis of triaxial compression test, the dynamic mechanics parameters are calculated and the reservoir brittleness is evaluated, which would provide a parameter basis for favorable fracturing stratum selection and scheme design of Shihezi formation reservoir in Yanchang gas field.

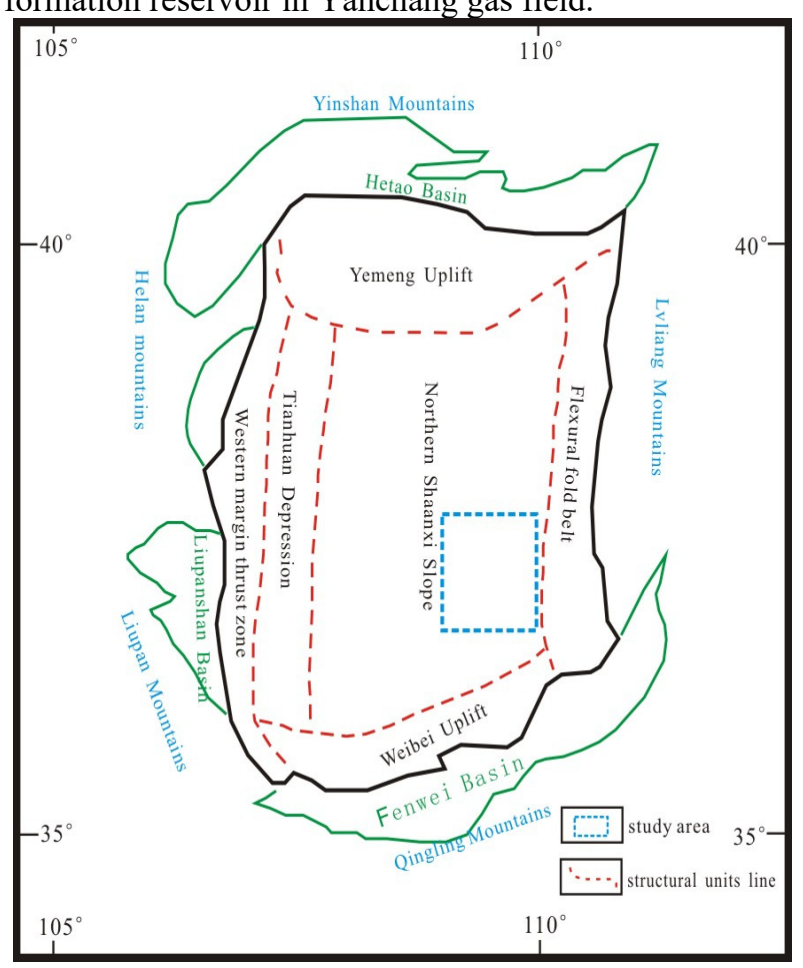

Fig 1. The study area in Ordos Basin 


\section{Triaxial compression test}

The sandstone samples are taken from Y-1, Y-2 and Y-3 well of Shihezi formation in Yanchang gas field (Fig. 2), with a total of 36 . The triaxial compression test adopts RMT-150C rock mechanics triaxial test system. All rock samples are processed into cylindrical shape. The specimens in compressive strength test are $\Phi 38.1 \mathrm{~mm} \times \mathrm{h} 76.2 \mathrm{~mm}$, and the specimens of tensile strength test are $\Phi 38.1 \mathrm{~mm} \times \mathrm{h} 19.0 \mathrm{~mm}$. The test results are shown in Table 1.
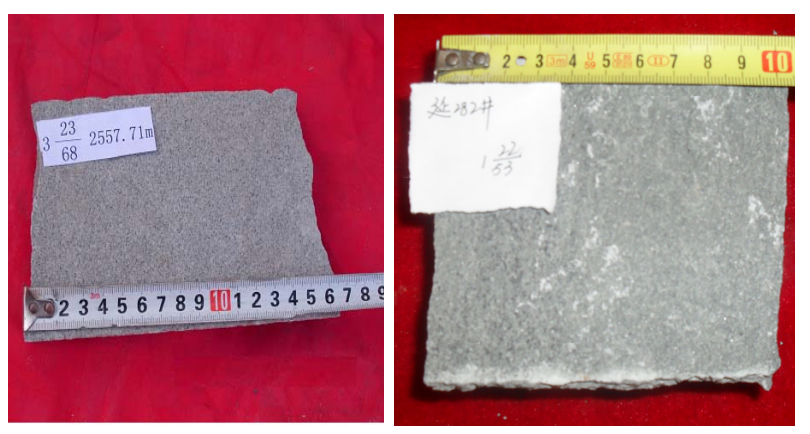

Fig 2. Photographs of sandstone core in Shihezi formation

Table 1. Results of triaxial compression test

\begin{tabular}{|c|c|c|c|c|c|c|}
\hline Well & Depth & Lithology & $\begin{array}{c}\text { Compressive } \\
\text { strength } \\
\sigma_{c}(\mathrm{MPa}) \\
\end{array}$ & $\begin{array}{c}\text { Tensile } \\
\text { strength } \\
\sigma_{t}(\mathrm{MPa})\end{array}$ & $\begin{array}{c}\text { Elastic } \\
\text { modulus } \\
\mathrm{E}(\mathrm{GPa})\end{array}$ & $\begin{array}{c}\text { Poisson's } \\
\text { ratio } \\
\mu\end{array}$ \\
\hline \multirow{6}{*}{$\mathrm{Y}-1$} & $2525.76-2525.94$ & \multirow{5}{*}{$\begin{array}{c}\text { Medium } \\
\text { sandstone }\end{array}$} & 149.560 & 12.314 & 24.300 & 0.251 \\
\hline & $2528.40-2528.61$ & & 153.461 & 12.764 & 23.734 & 0.254 \\
\hline & $2530.07-2530.34$ & & 176.625 & 14.675 & 26.560 & 0.249 \\
\hline & $2533.58-2533.75$ & & 190.185 & 15.802 & 26.955 & 0.241 \\
\hline & $2535.06-2535.18$ & & 171.443 & 14.245 & 25.262 & 0.263 \\
\hline & $2559.85-2559.96$ & \multirow{7}{*}{$\begin{array}{c}\text { Fine } \\
\text { sandstone }\end{array}$} & 177.741 & 16.710 & 25.382 & 0.265 \\
\hline \multirow{13}{*}{$\mathrm{Y}-2$} & $2562.06-2562.26$ & & 178.218 & 15.409 & 25.696 & 0.302 \\
\hline & $2565.26-2565.37$ & & 171.539 & 15.573 & 25.742 & 0.257 \\
\hline & $2568.56-2568.68$ & & 174.959 & 14.986 & 26.507 & 0.243 \\
\hline & $2571.80-2571.91$ & & 186.701 & 14.748 & 26.491 & 0.256 \\
\hline & $2576.03-2576.23$ & & 194.064 & 16.367 & 28.630 & 0.221 \\
\hline & $2580.44-2580.53$ & & 234.472 & 20.423 & 26.360 & 0.230 \\
\hline & $2583.69-2583.82$ & \multirow{8}{*}{ Sandstone } & 236.943 & 21.319 & 26.213 & 0.256 \\
\hline & $2586.02-2586.16$ & & 225.260 & 17.607 & 26.103 & 0.275 \\
\hline & $2589.31-2589.41$ & & 198.659 & 15.228 & 28.350 & 0.231 \\
\hline & $2593.66-2593.82$ & & 182.383 & 16.102 & 27.310 & 0.243 \\
\hline & $2595.82-2595.97$ & & 204.450 & 17.638 & 26.604 & 0.263 \\
\hline & $2598.97-2598.08$ & & 207.507 & 17.892 & 25.150 & 0.244 \\
\hline & $2602.20-2602.30$ & & 206.596 & 17.817 & 26.733 & 0.279 \\
\hline \multirow{17}{*}{ Y-3 } & $2605.42-2605.62$ & & 206.588 & 18.641 & 28.350 & 0.238 \\
\hline & $3102.2-3102.42$ & \multirow{16}{*}{$\begin{array}{c}\text { Fine } \\
\text { sandstone }\end{array}$} & 221.371 & 16.710 & 28.878 & 0.252 \\
\hline & $3104.63-3104.76$ & & 230.577 & 17.647 & 27.001 & 0.271 \\
\hline & $3106.88-3106.02$ & & 300.956 & 22.988 & 27.191 & 0.258 \\
\hline & $3109.02-3109.18$ & & 354.377 & 28.366 & 30.998 & 0.250 \\
\hline & $3112.38-3112.58$ & & 332.633 & 26.561 & 29.515 & 0.243 \\
\hline & $3115.76-3115.91$ & & 390.764 & 30.779 & 28.820 & 0.230 \\
\hline & $3118.08-3118.32$ & & 429.865 & 32.050 & 30.790 & 0.242 \\
\hline & $3120.42-3120.57$ & & 423.179 & 33.524 & 30.330 & 0.243 \\
\hline & $3122.78-3122.98$ & & 325.534 & 23.965 & 30.880 & 0.244 \\
\hline & $3125.22-3125.38$ & & 232.783 & 19.751 & 28.853 & 0.238 \\
\hline & $3128.52-3128.68$ & & 239.846 & 20.828 & 29.570 & 0.252 \\
\hline & $3131.38-3131.48$ & & 329.965 & 25.692 & 31.837 & 0.217 \\
\hline & $3133.68-3133.83$ & & 342.242 & 27.295 & 33.800 & 0.232 \\
\hline & $3136.28-3136.48$ & & 307.217 & 23.688 & 32.580 & 0.205 \\
\hline & $3139.68-3139.85$ & & 306.397 & 24.883 & 31.825 & 0.243 \\
\hline & $3141.96-3141.16$ & & 300.690 & 24.584 & 30.364 & 0.239 \\
\hline
\end{tabular}




\section{Rock mechanical characteristics of reservoir}

\subsection{Characteristics of elastic parameters}

The results of rock mechanics parameters of sandstone samples in Shihezi formation in Yanchang gas field (Table 1) show that the compressive strength and elastic modulus increase with the increase of burial depth, while the Poisson's ratio does not change significantly. The intersection diagrams of elastic modulus, Poisson's ratio and compressive strength (Fig. 3 and 4) show that compressive strength is closely related to elastic modulus, and increases linearly with the increase of elastic modulus, but negatively correlates with Poisson's ratio.

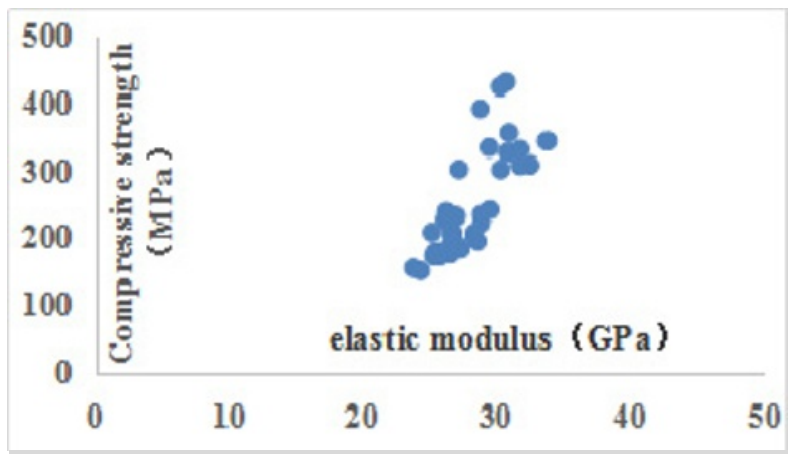

Fig 3. Compressive strength \& elastic modulus of sandstone samples

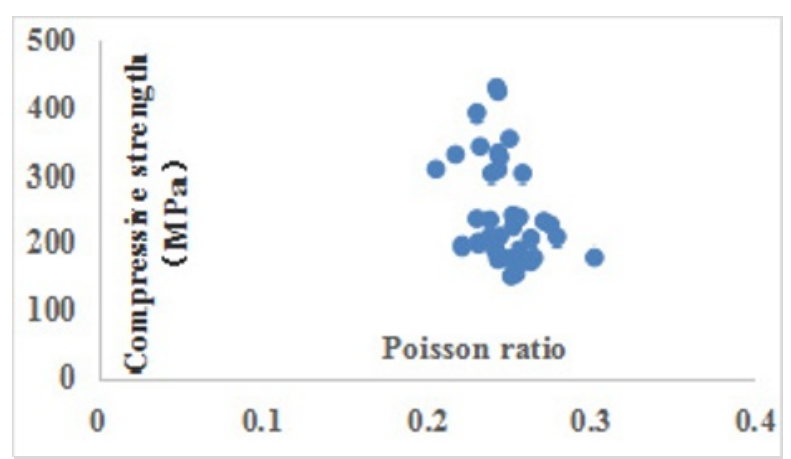

Fig 4. Compressive strength $\&$ Poisson's ratio of sandstone samples

\subsection{Fracturing characteristics of rock samples after triaxial compression test}

Rock mechanics parameters can reflect the ability of stratum to crack under outside stress ${ }^{[5,6]}$. Elastic modulus reflects the ability to maintain crack opening and expansion, and Poisson's ratio reflects the ability of rock to expand transversely under stress ${ }^{[7]}$. Generally speaking, elastic modulus and Poisson's ratio are combined to show the brittleness characteristics of the stratum. The larger the elastic modulus, the smaller the Poisson's ratio, the higher the brittleness of rock, the easier it is to form complex fracture network.

Through statistical analysis of fracturing modes of sandstone samples after triaxial compression test, the fracturing distribution characteristics of sandstone samples in the study area can be obtained (Fig. 5). The main fracturing mode of sandstone is multiple horizontal splitting, the main cracks are completely fractured, and many micro-cracks are formed around the main cracks.
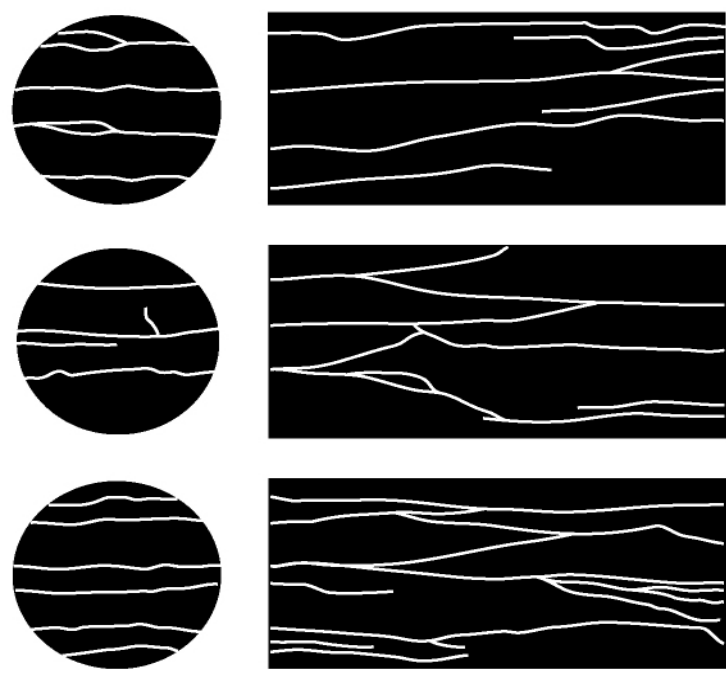

Fig 5. Fracturing mode of sandstone samples in the study area

\subsection{Mechanical brittleness characteristics}

Because rock brittleness is a comprehensive reflection of elastic modulus and Poisson's ratio, Rickman ${ }^{[8]}$ put forward a formula for calculating brittleness index based on rock mechanics parameters (Formula 3), namely, the normalized elastic modulus and Poisson's ratio are taken $50 \%$ respectively for calculation.

$$
\begin{gathered}
\Delta E=\frac{E-E_{\min }}{E_{\max }-E_{\min }} \times 100 \% \\
\Delta \mu=\frac{\mu_{\max }-\mu}{\mu_{\max }-\mu_{\min }} \times 100 \% \\
B=\frac{\Delta E+\Delta \mu}{2} \times 100 \%
\end{gathered}
$$

In the formula, $\Delta \mathrm{E}$ is the normalized elastic modulus, $\%, \mathrm{E}$ is the average elastic modulus of rock, $\mathrm{GPa}, \Delta \mu$ is the normalized Poisson's ratio, $\%, \mu$ is the average Poisson's ratio of rock, dimensionless, $\mathrm{B}$ is the brittleness index, \%, and subscript max and min represent the maximum and minimum values of the parameter in a certain stratum.

The brittleness index is calculated by formula (3). The brittleness index of Y-1 well is $51.2 \%$, that of Y-2 well is $51.4 \%$, and that of $\mathrm{Y}-3$ well is $46.1 \%$. It can be seen that the overall brittleness of the reservoir in Shihezi formation in Yanchang gas field is relatively high, and the brittleness index ranges from $46.1 \%$ to $51.4 \%$.

\section{Well logging Interpretation of mechanics parameter}

\subsection{Calculation of dynamic mechanics parameters}


The dynamic mechanics parameters of rock refer to the mechanics parameters determined by logging data or acoustic wave test. Based on Newton's law of motion and linear elasticity theory, under the assumption of rock isotropy, the relation between waves velocity and elastic parameters of rock can be obtained (4), (5).

$$
\begin{aligned}
& V_{p}=\sqrt{\frac{E_{d}\left(1-\mu_{d}\right)}{\rho\left(1+\mu_{d}\right)\left(1-2 \mu_{d}\right)}} \\
& V_{s}=\sqrt{\frac{E_{d}}{2 \rho\left(1+\mu_{d}\right)}}
\end{aligned}
$$

From the above equations, we can get the following (6), (7):

$$
\begin{aligned}
E_{d} & =\frac{\rho V_{p}^{2}\left(3 V_{p}^{2}-4 V_{s}^{2}\right)}{V_{p}^{2}-V_{s}^{2}} \\
\mu_{d} & =\frac{V_{p}^{2}-2 V_{s}^{2}}{2\left(V_{p}^{2}-V_{s}^{2}\right)}
\end{aligned}
$$

In the formula, $E_{d}$ is dynamic elastics modulus, $\mathrm{GPa}$, $\mu_{\mathrm{d}}$ is dynamic Poisson's ratio of rock, dimensionless, $\rho$ is volume density, $\mathrm{g} / \mathrm{cm}^{3}, \mathrm{~V}_{\mathrm{p}}$ is $\mathrm{P}$-wave velocity, $\mathrm{m} / \mathrm{s}$ and $\mathrm{V}_{\mathrm{s}}$ is $\mathrm{S}$-wave velocity, $\mathrm{m} / \mathrm{s}$.

It can be seen that when the density logging data and acoustic moveout of $\mathrm{p}$-wave and $\mathrm{S}$-wave by array acoustic logging are obtained, the dynamic elastic modulus and Poisson's ratio of rock at any depth can be calculated by formula (6), (7). The data obtained by this method are of high accuracy and reflect the rock mechanics characteristics dynamically and continuously. It is the most commonly used method for obtaining mechanics parameters at present. However, due to the high cost of array acoustic logging, S-wave logging data about most wells in Yanchang gas field could not be obtained. S-wave moveout calculation model is established by using limited conventional logging data in order to solve this problem. The relation formula of Pwave, S-wave moveout and density is established for calculating S-wave moveout of Shihezi formation in Yanchang gas field (8).

$$
\Delta t_{s}=\frac{\rho \Delta t_{p}{ }^{2}}{1.249 \Delta t_{P}+98.355 \rho-355.83}
$$

The results of S-wave moveout calculated in the study area are in good agreement with the measured results, and the error is less than $8 \%$, which prove this method is feasible and practicable.

\subsection{The conversion between dynamic and static parameter}

Because of the heterogeneity of the stratum, there are some differences between the dynamic mechanics parameters obtained by well logging and the static mechanics parameters obtained by triaxial compression test $^{[9]}$. Generally speaking, the dynamic elastic modulus is larger than the static elastic modulus. Linear regression is used on the dynamic and static elastic modulus and Poisson's ratio of the rock samples from Y$1, \mathrm{Y}-2$, and Y-3 well in study area, and the following relation (Fig. 5, 6) could be obtained.

$$
E_{s}=0.4142 E_{d}+10.769 \quad R^{2}=0.8387
$$

$$
\mu_{s}=1.1076 \mu d-0.068 \quad R^{2}=0.7366
$$

From Fig. 6 and Fig. 7, it can be seen that dynamic elastic modulus of the study area is larger than the static elastic modulus, while the dynamic Poisson's ratio and the static Poisson's ratio have little difference. Therefore, based on the dynamic mechanics parameters by logging interpretation and the conversion relation between the dynamic and static mechanics parameters, the continuous mechanics parameters profile of each well can be obtained, according to which, mechanical characteristics of the stratum could be evaluated.

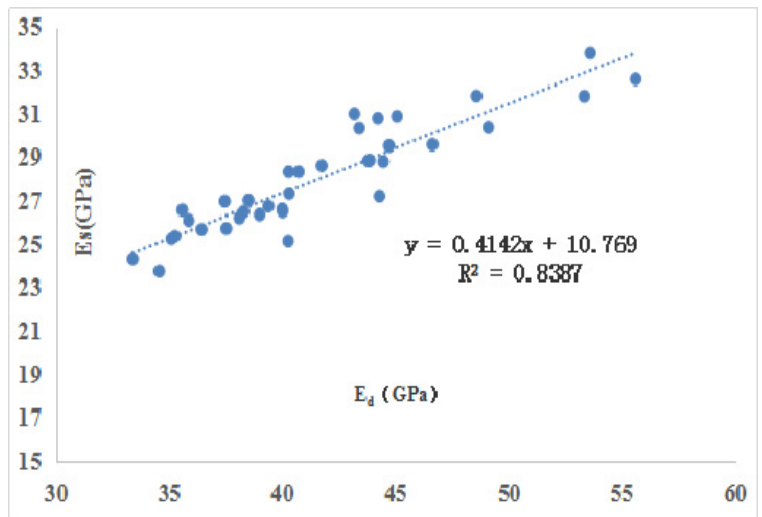

Fig 6. Conversion relation between dynamic and static elastic modulus in the study area

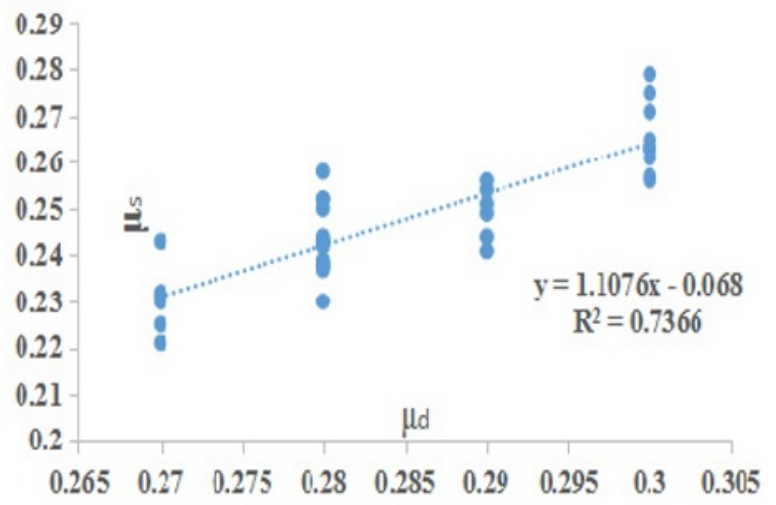

Fig 7. Conversion relation between dynamic and static Poisson's ratio in the study area

\subsection{Brittleness evaluation by well logging}

The mechanics parameter profile of well Y-2 in Shihezi formation in Yanchang gas field is obtained by well logging. The mechanical brittleness index of the sandstone stratum $(2560-2680 \mathrm{~m})$ is calculated by formula (3) and compared with the brittleness index calculated by mineral composition method (Figure 8). It can be found that the brittleness indexes calculated by the two methods have high goodness of fit, which could prove that the brittleness by logging interpretation is reliable.

From Figure 8, it can be seen that the overall brittleness index of the sandstone in Shihezi formation in Yanchang gas field is high, and it is easy to form complex fracture network and is beneficial for reservoir fracturing. 


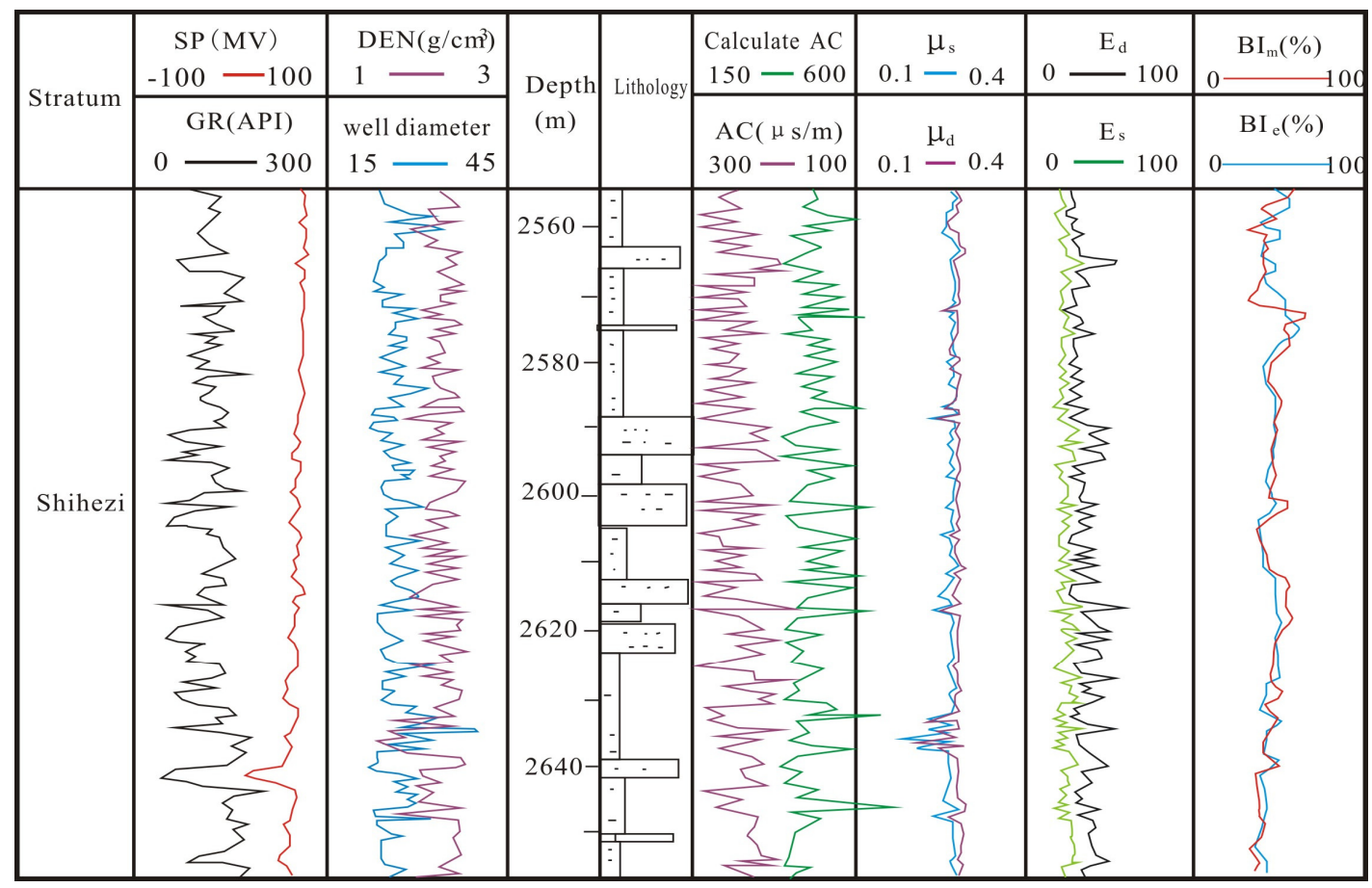

Fig 8. The analysis results of the brittleness in Shihezi formation in Yanchang gas field

\section{Conclusion}

Triaxial compression test in sandstone of Shihezi formation in Yanchang gas field shows that with the increase of burial depth, compressive strength and elastic modulus increase, while Poisson's ratio does not change significantly, the sandstone is mainly dominated by horizontal splitting, and its brittleness index ranges from $46.1 \%$ to $51.4 \%$. The mechanics parameters calculated by well logging are dynamic parameters, but the static parameters are needed in practical application. The conversion relations between the dynamic and static mechanics parameters in the study area are $E_{s}=0.4142 E_{d}+10.769 \quad\left(R^{2}=0.8387\right)$, and $\mu_{s}=1.1076 \mu_{d^{-}}$ $0.068\left(\mathrm{R}^{2}=0.7366\right)$. The brittleness indexes calculated by well logging and by mineral composition method have high goodness of fit. So the overall brittleness index of the sandstone in Shihezi formation in Yanchang gas field is high, and it is easy to form complex fracture network and is beneficial for reservoir fracturing.

\section{Acknowledgement}

This work was financially supported by Higher Education Funds of Gansu Province, project number 2015-148A, by Qingyang Natural Fund Project, project number ZJ201301, and also by Youth Technology Fund of Longdong University, project number XYZK1703.

\section{References}

1. Ganchuan $\mathrm{Xu}$, Guanghai Zhong, Bing Xie, et al. Shale Brittle Logging Evaluation Method Based on Petrophysical Experiments, Nature gas industry, (2014)
2. Quan Gao, Junliang Tao, Jianying Hu. Laboratory study on the mechanical behaviors of an anisotropic shale rock, Journal of Rock Mechanics and Geotechnical Engineering, (2015)

3. K. K. Chong, W. Griese, O .A. Jaripatke, et al. A Completions guide book to shale-play development:a review of successful approaches toward shale-play stimulation in the last two decades, Beijing,China:SPE International Oil and Gas Conference and Exhibition Luigi T. De Luca, Propulsion physics (EDP Sciences, Les Ulis, 2009)

4. R. M. Goktan, N. G. Yilmaz. A new methodology for the analysis of the relationship between rock brittleness index and drag pick cutting, The Journal of the South African Institute of Mining and Metallurgy, (2005)

5. Xiaoyan Qin, Zhenliang Wang.Brittle geophysical logging evaluation of continental shale based on rock mechanics characteristics. Progress in Geophysics, (2016)

6. J. A. Martin, geomechanical approach to evaluate brittleness using well logs: Mississippian limestone, Northern Oklahoma. Texas:The University of Texas at Arlington, ( 2015)

7. M. Josh, L. Esteban, C. D. Plane, et al. Laboratory characterisation of shale properties. Journal of Petroleum Science \& Engineering, (2012)

8. R. Rickman, M. J. Mullen, et al. A practical use of shale petrophysics for stimulation design optimization: all shale plays are not clones of the Barnett Shale. SPE Annual Technical Conference and Exhibition, Denver, Colorado, USA, (2008)

9. Zhuoying Fan, Chenyan Lin. Logging optimization modeling of rock brittleness index in dense strata, Journal of Petroleum, ( 2015) 